\title{
Quantitative analysis of trace elements in Podocarpus nagi seeds
}

\author{
Yang Yang ${ }^{1,3}$, Olagoke Zacchaeus Olatunde ${ }^{1}$, Jianping Yong ${ }^{2 *}$ and Canzhong $\mathrm{Lu}^{1,2 *}$ \\ ${ }^{1}$ Fujian Institute of Research on the Structure of Matter, Haixi Institute, Chinese Academy of Sciences, China \\ ${ }^{2}$ Xiamen Institute of Rare-earth Materials, Haixi Institute, Chinese Academy of Sciences, China \\ ${ }^{3}$ ShanghaiTechUniversity, China
}

\begin{abstract}
Podocarpus nagi is a tree belonging to the family of Podocarpaceae, which has ever been used for treatment of trauma, stop-bleeding, fractures, knife wounds, gunshot wounds, body odor, eye diseases, colds and rheumatoid arthritis in clinic. Some compounds have been isolated and their biological activities were also evaluated. it's seeds contains much oil and which can be used for food after refining or directly used industrially. In this work, the trace elements in the nuts, nut shell and oil residue were detected by the method of atomic absorption spectrum, which can provide reference for the further study.
\end{abstract}

\section{Mini-review}

Podocarpus nagi (Named Zhubai in Chinese) is a tree belonging to the family of Podocarpaceae, widely distributed in South District of the Yangtse River, such as Jiangxi, Zhejiang, Fujian, Hunan, Guangxi and Guangdong, etc. In Nanping, Sanming and Zhangzhou of Fujian Province, there are small scaled natural communities or artificial enclosure planting of the Podocarpus nagi, which is a native tree species of local place, which has ever been used for treatment of trauma, stopbleeding, fractures, knife wounds, gunshot wounds, body odor, eye diseases, colds and rheumatoid arthritis in clinic. Some compounds have been isolated and their biological activities were also evaluated [1-5]. Its seeds contain much oil and which can be used for food after refining or directly used industrially [6]. The contents of $\mathrm{Ca}, \mathrm{Fe}, \mathrm{Na}, \mathrm{Mg}$, $\mathrm{Mn}, \mathrm{Zn}, \mathrm{K}, \mathrm{Cu}$, and heavy metal elements such as $\mathrm{Cr}$ in the nuts, nut shell and oil residue were detected by the method of atomic absorption spectrum in this work.

The experimental procedure listed below: the nuts, nut shell and oil residue were dried at $60^{\circ} \mathrm{C}$ and powdered respectively. Each sample was weighed the given weight and diluted in $50 \mathrm{~mL}$ volumetric flask using the deionized water after nitrolysis. The trace elements in the nuts, nut shell and oil residue were detected using the atomic absorption spectrum. The nitrolysis processes (Figure 1) and articles results are listed in table 1, which provide the evidence for the further research.

Table 1. The content of the trace elements.

\begin{tabular}{|c|c|c|c|c|c|}
\hline \multirow{2}{*}{ Elements } & \multirow{2}{*}{ Stand curve } & \multirow{2}{*}{$\mathbf{R}^{2}$} & \multicolumn{3}{|c|}{ The content of the trace elements (mg/g) } \\
\cline { 3 - 6 } & & & nut shell & nuts & oil residue \\
\hline $\mathrm{Na}$ & $\mathrm{Y}=0.4876 \mathrm{X}-0.0168$ & 0.9990 & 0.088 & 0.064 & 0.092 \\
\hline $\mathrm{Mg}$ & $\mathrm{Y}=0.9391 \mathrm{X}+0.1272$ & 0.9989 & 0.315 & 0.0418 & 0.0813 \\
\hline $\mathrm{K}$ & $\mathrm{Y}=0.1452 \mathrm{X}+0.7814$ & 0.9998 & 0.558 & 0.769 & 0.797 \\
\hline $\mathrm{Ca}$ & $\mathrm{Y}=0.0393 \mathrm{X}+0.0269$ & 0.9996 & 0.324 & 1.310 & 0.526 \\
\hline $\mathrm{Mn}$ & $\mathrm{Y}=0.5738 \mathrm{X}+0.0695$ & 0.9989 & 0.021 & 0.028 & 0.126 \\
\hline $\mathrm{Zn}$ & $\mathrm{Y}=0.4649 \mathrm{X}+0.0359$ & 0.9994 & 0.006 & 0.042 & 0.036 \\
\hline $\mathrm{Fe}$ & $\mathrm{Y}=0.1117 \mathrm{X}+0.0071$ & 0.9996 & 0.060 & 0.039 & 0.032 \\
\hline $\mathrm{Cu}$ & $\mathrm{Y}=0.1575 \mathrm{X}+0.0009$ & 0.9997 & 0.008 & 0.018 & 0.021 \\
\hline $\mathrm{Cr}$ & $\mathrm{Y}=0.0213 \mathrm{X}+0.0009$ & 0.9989 & 0.038 & 0.026 & 0.015 \\
\hline
\end{tabular}

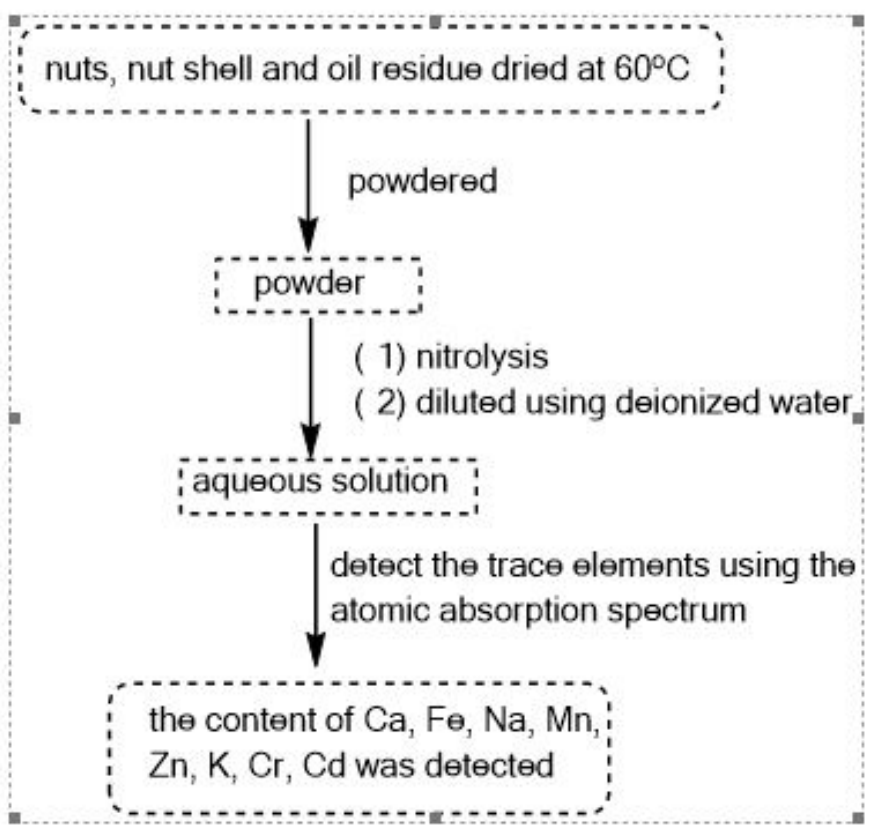

Figure 1. Processes of nitrolysis and detect the trace elements.

${ }^{\star}$ Correspondence to: Jianping Yong, Xiamen Institute of Rare-earth Materials, Haixi Institute, Chinese Academy of Sciences, Xiamen, 361021, China, Tel: +86-591-63173162, E-mail: jpyong@fjirsm.ac.cn

Canzhong $\mathrm{Lu}$, Xiamen Institute of Rare-earth Materials, Haixi Institute, Chinese Academy of Sciences, Xiamen, 361021, China, Tel: +86-591-83705794, E-mail: czlu@fjirsm.ac.cn

Key words: Podocarpus nagi, seeds, trace element, elemental analysis

Received: January 04, 2019; Accepted: January 22, 2019; Published: January 28, 2019 


\section{Acknowledgements}

This work was financially supported by the National Natural Science Foundation of China (21875252) and the Project of The Plan of Xiamen Science and Technology (3502ZCQ20171000).

\section{References}

1. Liao ZY, Wei W (2015) Studies on Volatile Constituents and Their Anti-tumor Activities from the Peel and Shell of Podocarpus nagi Fruits. Herald Med 34: 609-612.

2. Dai B (2009) Chinese modern Yao medicine. Nanning: Guangxi science and Technology Publishers: 257-259.
3. Xu YM, Fang SD, He QM (1990) The Chemical Constituents from Podocarpus Fleuryi Hickel. Acta Botanica Sinica 32: 302-306.

4. Xu YM, Fang SD, He QM (1991) The Structure of a New Biflavone from Podocarpus Fleuryi. Acta Botanica Sinica 33: 162-163.

5. Yang Y, Yong J, Lu C (2018) Chemical and biological progress of Podocarpus nagi Biomed Res Rev 2: 1-5.

6. Chinese Flora Editorial Board of Chinese Academy of Sciences (1987) Flora of China Beijing: Science Press 7: 404-405.

Copyright: (2019 Yang Y. This is an open-access article distributed under the terms of the Creative Commons Attribution License, which permits unrestricted use, distribution, and reproduction in any medium, provided the original author and source are credited. 